\title{
Assessment of the frequency of tarsal tunnel syndrome in rheumatoid arthritis
}

\author{
Mehtap Kalçı Ünan®, Özge Ardıçoğlu@, Nevsun Pıhtılı Taş@, Rabia Aydoğan Baykara@, Ayhan Kamanl@® \\ Department of Physical Medicine and Rehabilitation, Frrat University, Faculty of Medicine, Elazığ, Turkey
}

Received: June 12, 2020 Accepted: August 12, 2020 Published online: December 01, 2021

\begin{abstract}
Objectives: In this study, we aimed to determine the frequency of tarsal tunnel syndrome (TTS) in rheumatoid arthritis (RA) patients.

Patients and methods: Thirty RA patients ( 1 male, 29 females; mean age: $41.9 \pm 10.1$ years; range, 26 to 65 years) who met the American College Rheumatology (ACR) classification criteria and 20 healthy volunteers ( 1 male, 19 females; mean age: $39.3 \pm 10.8$ years; range, 26 to 60 years) without any complaints between August 2006 and October 2007 were included in the study. Demographic characteristics of the study group were assessed and neurological examinations were performed. The Tinel's sign was checked to provoke the TTS symptoms. Disease severity was measured using Visual Analog Scale (VAS), Disease Activity Score-28 (DAS28), erythrocyte sedimentation rate (ESR) and C-reactive protein (CRP). The health-related quality of life and disability status were determined using the Health Assessment Questionnaire (HAQ), Short Form 36 (SF-36), Foot Function Index (FFI), and VAS (0-100 mm). The positional relationship of the foot pain was questioned with VAS. The 100-m walking distance of the patient and control groups were calculated.
\end{abstract}

Results: Bilateral TTS was detected in 10 of the patients (33.3\%) with rheumatoid arthritis. No relationship with the TTS disease duration, seropositivity, rheumatoid nodule, joint deformities, corticosteroid use, and DAS28 score were found. In correlation with TTS, foot and ankle joint were the first involved joints at the beginning of RA disease $(\mathrm{p}<0.005)$. The Tinel's sign was found to be $45 \%$ positive in patients with TTS. The 100-m walking time was significantly longer in RA patients compared to the control group $(\mathrm{p}<0.0001)$.

Conclusion: Tarsal tunnel syndrome is commonly seen in RA and its incidence increases in patients with primary foot involvement. Therefore, caution should be taken against the entrapment neuropathies in these patients, and they should be supported by electrophysiological practices, when the diagnosis is necessary.

Keywords: Entrapment neuropathy, rheumatoid arthritis, tarsal tunnel syndrome.

Rheumatoid arthritis (RA) is a chronic, systemic, inflammatory, rheumatic disease that affects the synovial joints primarily and develops from unknown causes. $^{[1-4]}$ The disease mainly affects the hand, wrist and foot joints; however, it can also involve all other synovial joints such as the knee, ankle, hip, elbow and shoulder. ${ }^{[1]}$

In patients with $\mathrm{RA}$, the foot involvement is as frequent as the hand involvement. ${ }^{[5]}$ It was reported as $38 \%$ by Bukhari et al. ${ }^{[6]}$ and shown to be frequent, particularly in the early periods of the disease. As the disease progresses, the incidence of foot involvement also increases..$^{[7]}$ The metatarsophalangeal joints of the feet are affected mostly in RA. ${ }^{[8]}$ Early forefoot involvement has been shown to be an indicator of the aggressive disease, and early erosions in the metatarsophalangeal joints is seen in $10 \%$ of the patients. $^{[5-7]}$

Entrapment neuropathies are frequently seen in RA. The involvement is usually in the form of mononeuritis multiplex. Median, ulnar, peroneal, and tibial nerves are affected the most commonly.

Tarsal tunnel syndrome (TTS) is the entrapment neuropathy of the posterior tibial nerve and/or its

Corresponding author: Nevsun Pıhtılı Taş, MD. Elazığ Fethi Sekin Şehir Hastanesi Fiziksel Tıp ve Rehabilitasyon Kliniği, 23280 Elazı̆̆, Türkiye. e-mail: nevsunpihtili@gmail.com 
terminal branches (i.e., calcaneal, medial plantar [MP], and lateral plantar [LP] branches) which develops in the fibro-osseous tunnel, under the flexor retinaculum and behind the medial malleolus of the ankle. ${ }^{[9]}$ The posterior tibial nerve, tibial artery, tibial vein, and, also, the tendons of tibialis posterior, flexor digitorum longus and flexor hallucis longus muscles pass through the tarsal tunnel (Figure 1). ${ }^{[10-14]}$

Tarsal tunnel syndrome is clinically characterized by local tenderness behind the medial malleolus, pain in the feet and heels, paresthesia and heat followed by numbness and tingling. Pain and paresthesia progressively become more permanent and more severe and may spread toward the posterior or medial (Valleix phenomenon) or distal (Tinel's sign) of the leg toward proximally.

Detailed history of patients and physical examination findings along with and electrophysiological studies are used in the diagnosis of TTS. ${ }^{[15]}$ Foot and ankle radiographs are useful in the evaluation of bone deformities and abnormalities. Computed tomography is helpful in diagnosis. Magnetic resonance imaging (MRI) and ultrasonography (USG), which have become popular recently, are used in the evaluation of soft tissues. ${ }^{[16,17]}$

Treatment modality of TTS should be targeting the etiology. ${ }^{[11]}$ Initially, conservative treatment should be initiated with non-steroidal anti-inflammatory drugs (NSAIDs) and other agents which reduce and prevent neuropathic pain. Also, local steroid injections are useful. Orthosis that limits the pronation of the ankle may help to reduce nerve compression. Surgical treatment should be indicated, if symptoms have persisted for six months or longer and conservative treatment has failed. Of note, negative electrophysiological studies do not rule out the diagnosis of TTS. The electrophysiological studies are usually supportive in the diagnosis of TTS; however, clinical symptoms and signs of the patient are the main determinants in diagnosis and treatment. ${ }^{[18]}$

In this pilot study, we aimed to examine the frequency of TTS and foot involvement, and to identify possible relationship with other clinical variables in RA patients.

\section{PATIENTS AND METHODS}

This pilot study was designed as a cross-sectional study and conducted at Firat University, Faculty of Medicine, Department of Physical Medicine and Rehabilitation, Rheumatology Unit between August 2006 and October 2007. Thirty RA patients (1 male, 29 females; mean age: $41.9 \pm 10.1$ years; range, 26 to 65 years) who met the American College Rheumatology (ACR) classification criteria and 20 healthy volunteers ( 1 male, 19 females; mean age: $39.3 \pm 10.8$ years; range, 26 to 60 years) without any foot complaints between August 2006 and October 2007 were included in the study. Patients with a history of other metabolic diseases known to affect the electroneurophysiology study such as diabetes mellitus; patients who were pregnant or had an autoimmune disease such as hypothyroidism, those undergoing hip arthroplasty, surgery for the lumbar region; and
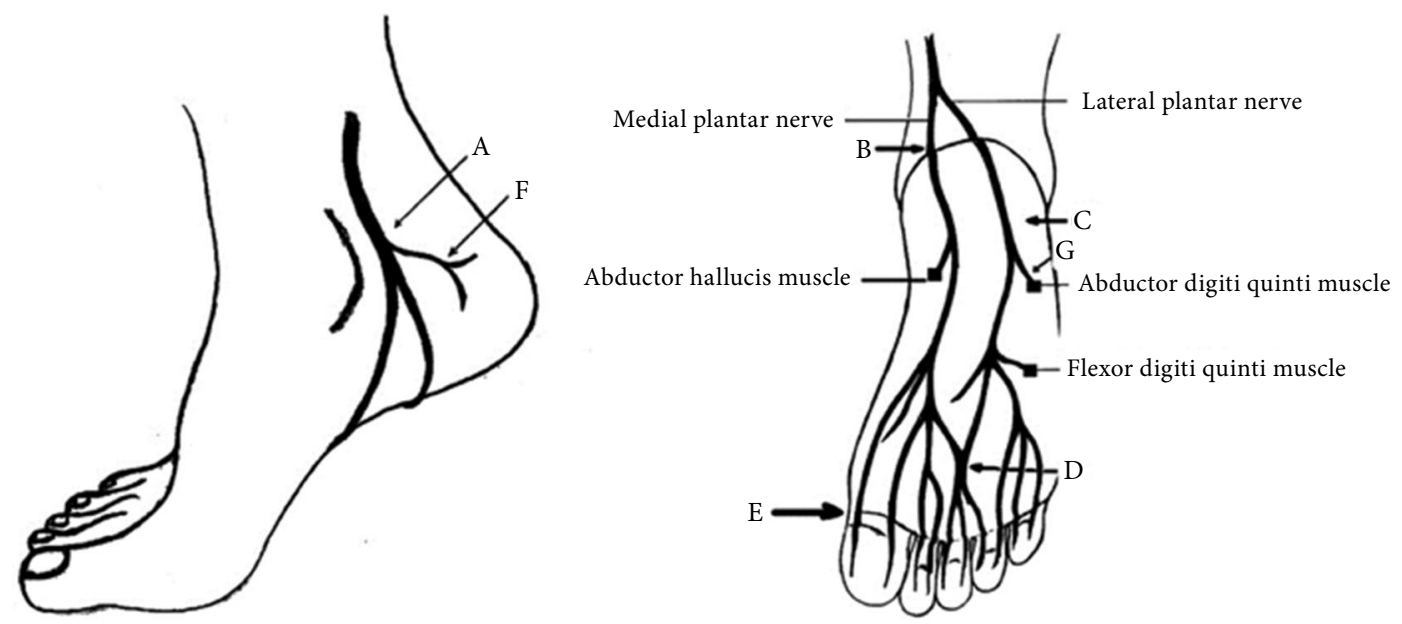

Figure 1. Trapping sites of the tibial nerve.

A: Tarsal tunnel (before leaving the branches). B: Medial plantar neuropathy. C: Lateral plantar neuropathy. D: Morton's neuroma. E: Joplin's neuroma. F: Medial calcaneal neuropathy. G: Inferior calcaneal neuropathy. ${ }^{[1]}$ 
those having a history of fracture, trauma, and/or operation for feet and ankles were excluded from the study. A written informed consent was obtained from each participant. The study protocol was approved by the Firat University, Faculty of Medicine Ethics Committee (date/no: 2005-2006/584). The study was conducted in accordance with the principles of the Declaration of Helsinki.

In this study, selection of the patients was done cross-sectionally and patients with or without foot pain, active or non-active, and using or not using disease-modifying antirheumatic drugs (DMARDs) and steroids were randomly included in the study.

Demographic data including age, sex, weight and height and clinical data including the time of the disease onset, duration of morning stiffness, other comorbid diseases, the use, dose, and duration of steroids, DMARDs, and NSAIDs for the study group were registered in detail. Hemoglobin, hematocrit, platelet count, white blood cell count, erythrocyte sedimentation rate (ESR), C-reactive protein (CRP) and rheumatoid factor (RF) values were measured.

The 100-m walking time for the patients in both groups was calculated in sec. The foot pain of the patient, its severity, and its relation with the position were assessed using the Visual Analog Scale (VAS).

The Health Assessment Questionnaire (HAQ) as a general health status questionnaire, the Foot Function Index (AFI), the Short Form 36 (SF-36), and VAS-pain were administered to both groups by a single clinician who was blind to the laboratory results of the patients.

The Tinel's sign was used as the main clinical evaluation of TTS. It is the tingling feeling with pain and numbness in the medial one-third of the foot base after the percussion of the tibial nerve at the upper border of the tarsal tunnel behind the medial malleolus. The positive percussion mark can be seen in all entrapped neuropathies. ${ }^{[19]}$ Symptoms are exacerbated by the pronation of anterior foot. Another provocative test is the compaction of the posterior tibial nerve by compressing the ankle to dorsiflexion and eversion position. ${ }^{[15]}$ Neurological examinations were carried out in both groups. During the examination, the Tinel's sign was also evaluated in detail to provoke the tibial nerve.

The electrophysiological examination was performed in the electrophysiology laboratory using the Medelec Synergy Electroneuromyography (ENMG) device (Medtronic, Keypoint ${ }^{\circledR}$, Skovlunde, Denmark). The room temperature was kept between 26 to $32^{\circ} \mathrm{C}$. The TTS ENMG protocol was administered bilaterally to the lower extremities of the patients in both the study and control groups by the same researcher. The reference values of lower extremity nerve conduction studies are given in Table $1 .{ }^{[1]}$ The difference in terminal latency of the MP and LP nerves over $1 \mathrm{msec}$ may be considered as TTS. ${ }^{[20,21]}$

In addition to TTS diagnosis, there should be conditions such as the decrease of the velocity in MP and LP sensorial nerve conduction studies, decrease in the amplitude, or sensory nerve action potential (SNAP) amplitude unable to be measured. The reference values for the MP and LP sensorial nerve conduction studies are summarized in Table 2. ${ }^{[18]}$

\section{Statistical analyzes}

Statistical analysis was performed using the SPSS for Windows version 12.0 software (SPSS Inc., Chicago, IL, USA). Descriptive data were expressed in mean \pm standard deviation (SD), median (min-max) or number and frequency. The distribution of the normality was checked using the independent t-test. Mann-Whitney $\mathrm{U}$ test was used to evaluate nonparametric data. The Spearman rho coefficient was used for intra-group comparisons. A $p$ value of $<0.05$ was considered statistically significant.

\begin{tabular}{|lccc|}
\multicolumn{5}{c}{ TABLE 1 } \\
The reference values of lower extremity nerve conduction studies \\
\begin{tabular}{|lccc} 
Nerve & Amplitude $(\mu \mathrm{V})$ & Conduction velocity $(\mathrm{m} / \mathrm{sn})$ & Distal latency $(\mathrm{ms})$ \\
\hline Peroneal nerve & $\geq 2.0$ & $\geq 44$ & $\leq 6.5$ \\
Tibial nerve & $\geq 4.0$ & $\geq 41$ & $\leq 5.8$ \\
Sural nerve & $\geq 6.0$ & $\geq 40$ & $\leq 4.4$ \\
Medial plantar nerve & $\geq 4.0$ & $\geq 41$ & $\leq 5.8$ \\
Lateral plantar nerve & $\geq 3.0$ & $\geq 41$ & $\leq 6.3$ \\
\hline
\end{tabular}
\end{tabular}




\begin{tabular}{|lcc|}
\multicolumn{4}{c|}{ TABLE 2} \\
\multicolumn{4}{|c|}{ The reference values for the MP and LP sensorial nerve conduction studies } \\
\hline & Amplitude $(\mu \mathrm{V})$ & Conduction velocity $(\mathrm{m} / \mathrm{sn})$ \\
\hline Medial plantar pure sensory & $\geq 2$ & $\geq 35$ \\
Lateral plantar pure sensory & $\geq 1$ & $\geq 35$ \\
Medial plantar mixed sensory & $\geq 3$ & $\geq 45$ \\
Lateral plantar mixed sensory & $\geq 3$ & $\geq 45$ \\
\hline MP: Medial plantar; LP: Lateral plantar. & & \\
\hline
\end{tabular}

\section{RESULTS}

A total of 100 feet in 30 RA patients and 20 healthy controls were included in this study. Of the patients, $80 \%(n=24)$ were seropositive. Baseline demographic and clinical characteristics of the patient and control groups are summarized in Table 3.

The mean disease duration in the RA patients was 8.5 (range, 1 to 28 ) years. Among the RA patients, $26(91.7 \%)$ had pain complaints about their both feet, as three patients (91.7\%) had pain only in their one foot (two right, one left). In one patient (8.33\%), no foot pain was observed. The Tinel's sign was found to be positive in bilateral feet of eight patients (24\%) and right foot of two patients $(6 \%)$ in the examinations. The other neurological examination findings of the patients were normal. In RA patients with TTS, the Tinel's sign was positive for bilateral feet in four patients (45\%) and right foot for one patient (45\%).

When the 100-m walking distance was compared between the patient and control groups, the mean duration in patients with RA was longer than the control group ( $95.2 \pm 11.2$ vs. $84.4 \pm-6.7$, respectively; $\mathrm{p}<0.0001)$.
There was no significant difference in the peroneal motor amplitude, latency, and neural conduction velocity (NCV) values between the patient and control groups ( $\mathrm{p}>0.05)$. Also, there was no significant difference in the right tibial motor latency between the groups $(\mathrm{p}>0.05)$. However, the right tibial motor amplitude and NCV in the RA patient group were lower than the control group, indicating a significant difference $(\mathrm{p}<0.05)$. There was no significant difference in the left tibial motor latency, amplitude, and NCV values between the patient and control groups ( $p>0.05$ ). In addition, there was no significant difference in the right and left sural sensory latencies and sensory conduction velocity (SCV) values between the patient and control groups ( $>0.05)$. However, the right and left sural sensory amplitude values were lower in the patient group, compared to the control group, indicating a significant difference $(\mathrm{p}<0.05)$. The peroneal amplitude values of two RA patients and one healthy individual were found to be at the lower limits $(1.8,1.8$, and 1.0 , respectively). Routine lower extremity neural conduction values of the study group are summarized in Table 4 . The left $\mathrm{M} / \mathrm{H}$ amplitude was higher in the patient group, indicating a significant difference $(\mathrm{p}<0.05)$. However, there was no significant

\begin{tabular}{|c|c|c|c|c|c|}
\hline \multicolumn{6}{|c|}{$\begin{array}{l}\text { TABLE } 3 \\
\text { The demographic characteristics of the patient and control groups }\end{array}$} \\
\hline & \multicolumn{2}{|c|}{$\begin{array}{l}\text { Rheumatoid arthritis } \\
\qquad(\mathrm{n}=30)\end{array}$} & \multicolumn{2}{|c|}{$\begin{array}{c}\text { Control } \\
(\mathrm{n}=20)\end{array}$} & \multirow[b]{2}{*}{$p$} \\
\hline & $\mathrm{n}$ & Mean \pm SD & $\mathrm{n}$ & Mean \pm SD & \\
\hline Age & & $41.9 \pm 10.1$ & & $39.3 \pm 10.8$ & $>0.05$ \\
\hline Sex & & & & & $>0.05$ \\
\hline Female & 29 & & 19 & & \\
\hline Male & 1 & & 1 & & \\
\hline Weight (kg) & & $69.5 \pm 11.6$ & & $66.3 \pm 9.5$ & $>0.05$ \\
\hline Height $(\mathrm{cm})$ & & $161.1 \pm 6.5$ & & $159.7 \pm 5.0$ & $>0.05$ \\
\hline Body mass index $\left(\mathrm{kg} / \mathrm{m}^{2}\right)$ & & $26.8 \pm 4.6$ & & $25.9 \pm 3.2$ & $>0.05$ \\
\hline
\end{tabular}




\begin{tabular}{|c|c|c|c|}
\hline \multicolumn{4}{|c|}{$\begin{array}{l}\text { TABLE } 4 \\
\text { Routine lower extremity neural conduction values of the study group }\end{array}$} \\
\hline & $\begin{array}{l}\text { Rheumatoid } \\
\text { arthritis }(n=30)\end{array}$ & $\begin{array}{c}\text { Control } \\
(\mathrm{n}=20)\end{array}$ & \\
\hline & Mean \pm SD & Mean \pm SD & $p$ \\
\hline Right tibial motor latency & $3.4 \pm 0.6$ & $3.4 \pm 0.7$ & $>0.05$ \\
\hline Right tibial motor amplitude & $17.4 \pm 5.4$ & $22.1 \pm 8.4$ & $<0.05$ \\
\hline Right tibial NCV & $51.5 \pm 7.5$ & $53.1 \pm 3.2$ & $<0.05$ \\
\hline Left tibial motor latency & $3.5 \pm 0.6$ & $3.4 \pm 0.6$ & $>0.05$ \\
\hline Left tibial motor amplitude & $18.4 \pm 5.6$ & $22.3 \pm 7.5$ & $>0.05$ \\
\hline Left tibial NCV & $48.8 \pm 10.1$ & $51.1 \pm 2.8$ & $>0.05$ \\
\hline Right peroneal motor latency & $3.7 \pm 0.5$ & $3.8 \pm 0.7$ & $>0.05$ \\
\hline Right peroneal motor amplitude & $7.4 \pm 4.1$ & $9.2 \pm 4.3$ & $>0.05$ \\
\hline Right peroneal NCV & $50.9 \pm 4.5$ & $49.7 \pm 11.2$ & $>0.05$ \\
\hline Left peroneal motor latency & $3.7 \pm 0.5$ & $3.6 \pm 1.1$ & $>0.05$ \\
\hline Left peroneal motor amplitude & $7.1 \pm 3.5$ & $8.3 \pm 3.5$ & $>0.05$ \\
\hline Left peroneal NCV & $51.2 \pm 4.2$ & $50.2 \pm 4.4$ & $>0.05$ \\
\hline Right sural sensory latency & $3.6 \pm 0.6$ & $3.7 \pm 0.5$ & $>0.05$ \\
\hline Right sural sensory amplitude & $11.7 \pm 8.5$ & $14.5 \pm 5.6$ & $<0.05$ \\
\hline Right sural SCV & $50.6 \pm 6.5$ & $51.6 \pm 6.0$ & $>0.05$ \\
\hline Left sural sensory latency & $3.6 \pm 0.6$ & $3.7 \pm 0.6$ & $>0.05$ \\
\hline Left sural sensory amplitude & $10.5 \pm 5.9$ & $13.9 \pm 6.5$ & $<0.05$ \\
\hline Left sural SCV & $49.8 \pm 5.8$ & $49.1 \pm 4.7$ & $>0.05$ \\
\hline
\end{tabular}

difference in the right and left $\mathrm{H}$ latencies, right and left $\mathrm{M} / \mathrm{H}$ latencies and right $\mathrm{M} / \mathrm{H}$ amplitudes between the patient and control groups ( $>>0.05)$. The H-reflex values of the study group are shown in Table 5.

In the patient group, the right MP pure sensory SNAP amplitude in three patients, the left LP pure sensory SNAP amplitude in three, patients and right
LP pure sensory SNAP amplitude in one patient could not be obtained.

Furthermore, TTS (33.3\%) was found in 20 feet (bilateral, $\mathrm{n}=10$ ) of the 60 feet of patients with RA. There was a decrease in both MP and LP nerve velocities in the patients with TTS. The electrophysiological findings of the healthy controls were found to be normal.

\begin{tabular}{|c|c|c|c|}
\hline \multicolumn{4}{|c|}{$\begin{array}{c}\text { TABLE } 5 \\
\text { The H reflex values of the study group }\end{array}$} \\
\hline & $\begin{array}{l}\text { Rheumatoid } \\
\text { arthritis }(n=30)\end{array}$ & $\begin{array}{l}\text { Control } \\
(n=20)\end{array}$ & \\
\hline & Mean \pm SD & Mean \pm SD & $p$ \\
\hline Left $\mathrm{H}$ latency & $30.0 \pm 2.2$ & $29.9 \pm 2.1$ & $>0.05$ \\
\hline Left M-H latency & $27.3 \pm 1.9$ & $28.1 \pm 1.9$ & $>0.05$ \\
\hline Left $\mathrm{M} / \mathrm{H}$ amplitude & $3.6 \pm 3.2$ & $2.0 \pm 1.8$ & $<0.05$ \\
\hline Right $\mathrm{H}$ latency & $30.3 \pm 2.3$ & $28.2 \pm 6.1$ & $>0.05$ \\
\hline Right M-H latency & $27.7 \pm 1.8$ & $28.0 \pm 1.4$ & $>0.05$ \\
\hline Right $\mathrm{M} / \mathrm{H}$ amplitude & $2.5 \pm 1.6$ & $1.8 \pm 1.4$ & $>0.05$ \\
\hline SD: Standard deviation. & & & \\
\hline
\end{tabular}




\section{DISCUSSION}

Rheumatoid arthritis is a chronic, multisystemic, inflammatory rheumatic disease which primarily affects the synovial joints. ${ }^{[1-4]}$ The most common cause of the neurological involvement in RA is the neural compressions. ${ }^{[22]}$ Tarsal tunnel syndrome is an entrapment neuropathy that occurs when the posterior tibial nerve and/or one of its terminal branches are affected in the tarsal tunnel..$^{[9,23]}$ The etiology of TTS is multifactorial. The most common cause of TTS is idiopathic. The cause of TTS was found to be idiopathic in 39 to $43 \%$ of the cases in the non-surgical series. ${ }^{[1]}$ Among the known causes, trauma accounts for about one-third of all cases. One of the other two major causes of TTS are empty field lesions and foot deformities. ${ }^{[1]}$

Clinical examination and imaging modalities such as MRI and USG are used for the diagnosis of TTS. The electrophysiological studies confirm the diagnosis of TTS. These studies are feasible tests in 90 to $100 \%$ of the patients for TTS diagnosis. ${ }^{[1]}$

In the literature, there are several studies investigating the prevalence of TTS in RA. In a study, Baylan et al. ${ }^{[24,25]}$ found the prevalence of TTS in RA to be $25 \%$. In our study, the frequency of TTS in RA was $33.3 \%$, a slightly higher than the aforementioned study.

Many of the electrophysiological techniques recommend the measurement of plantar NCV for the diagnosis of TTS. In our study, the distal motor latency (DML) of both MP and LP nerves were found to be within the normal values in both RA and control groups. There was no extension in DML in both groups. The specificity of mixed neural conduction studies in TTS diagnosis is higher than pure sensory conduction studies, and mixed neural conduction studies are more sensitive to the early changes than to pure sensory conduction studies.

In accordance with the TTS study protocol, both pure sensory and mixed sensory conduction studies of the MP and LP nerves were performed. The SNAP amplitude in mixed sensory conduction studies of the patient and control groups was simpler and easier to obtain than in the pure sensory conduction studies. Another averaging was not required. Therefore, when the MP and LP SCV of the study group were examined, the mixed sense conduction rates were specifically considered. Bilateral TTS was detected in $10(33.3 \%)$ of 30 RA patients. The reason for this rate being higher than the previously conducted studies is probably the fact that TTS was mainly studied sensorially.
Tarsal tunnel syndrome is usually seen as unilateral. Galardi et al. ${ }^{[18]}$ found the rate of bilateral presence to be $8 \%$ in their study, while Mondelli et al. ${ }^{[9]}$ reported $16 \%$. In our study, however, all 10 patients with TTS had bilateral TTS. This result may be related to the fact that the patients studied were RA patients and the disease is a systemic disease in nature.

Tarsal tunnel syndrome is clinically characterized by pain, paresthesia and/or numbness in the foot and ankle. In our study, only one (3.3\%) RA patient had free from foot pain complaints. Of the remaining patients, $26(86.7 \%)$ had complaints in both feet and three (10\%) had complaints only in one foot. The joint which the disease started was associated with ankle and foot joints in more than one-third of the patients who had TTS $(\mathrm{p}<0.05)$. This finding suggests a significant relationship between the process and severity of the affected foot joints and TTS. In addition, only half of the patients diagnosed with TTS had typical complaints and TTS was not detected in the electrophysiological studies of five patients with similar complaints. These results suggest that, in the entrapment neuropathy diagnosis, the medical history taken from the patient is not enough and electrophysiological studies should support the diagnosis. These studies are also helpful to avoid treatment delay. Although the tibial nerve DML and conduction velocities were similar in both the patient and control groups, the significant difference in the right-side comparisons may be considered significant, showing the potential for dominant extremity to be more affected in these patients.

The H-reflex is normal in TTS, but it may be found to be abnormal in polyneuropathies, proximal tibial neuropathies, sciatic and lumbosacral plexus lesions, and S1 radiculopathies. ${ }^{[10]}$ The H-reflex latency and $\mathrm{M}-\mathrm{H}$ latency values were evaluated in RA patients and control group in our study and were found to be within the normal reference range, indicating no significant difference between the two groups ( $p>0.05)$.

In the general health assessments of patients with RA, there was a significant difference in all the subscales of HAQ and SF-36, compared to the control group $(\mathrm{p}<0.01)$. Entrapment neuropathies may possibly contribute negatively to this in later periods.

The low number of patients we selected due to the technical difficulty of EMG performed for the evaluation of tarsal tunnel syndrome and the small number in the control group are among the limitations of our study. we also think it is necessary to compare 
other diseases with different age groups and as a control group.

In conclusion, entrapment neuropathies are among the most common clinical variants in the peripheral nervous system involvement of the patients with RA. In this study, the frequency of TTS electrophysiologically was higher in patients with RA than in the previous studies. Therefore, the evaluation of the patients with RA should be done more carefully. The diagnosis is recommended to be supported by electrophysiological studies, when the medical history and physical examination are not sufficient.

\section{Declaration of conflicting interests}

The authors declared no conflicts of interest with respect to the authorship and/or publication of this article.

\section{Funding}

The authors received no financial support for the research and/or authorship of this article.

\section{REFERENCES}

1. Felson D. Epidemiology of the rheumatic diseases. In: Koopman WJ, editor. Arthritis and Allied Conditions a Textbook of Rheumatology. Philadelphia: Lippincott Williams \& Wilkins; 2001. p. 580-603.

2. Haris ED. Etiology and patogenesis of rheumatoid arthritis. In: Kelley WN, Harris ED, Ruddy S, editors. Textbook of Rheumatology. 6th ed. Philedelphia: WB Saunders; 1993. p. 833-73.

3. Croia C, Bursi R, Sutera D, Petrelli F, Alunno A, Puxeddu I. One year in review 2019: pathogenesis of rheumatoid arthritis. Clin Exp Rheumatol 2019;37:347-57.

4. Sparks J. Rheumatoid arthritis. Ann Intern Med 2019;170:1-16.

5. Wollheim AF. Rheumatoid arthritis the clinical picture. In: Maddison PJ, Isenberg DA, Woo P, Glass DN, editors. Oxford Textbook of Rheumatology. 4th ed. Atlanta: Oxford Universty Press; 1998. p. 1004-31.

6. Bukhari M, Barret J, Harison B, Scott D, Silan D. Baseline characteristics of patients with rheumatoid arthritis who erode initially only in their feet. Arthritis \& Rheumatism 1998;41:S54

7. Hulsmans HM, Jacobs JW, van der Heijde DM, van AlbadaKuipers GA, Schenk Y, Bijlsma JW. The course of radiologic damage during the first six years of rheumatoid arthritis. Arthritis Rheum 2000;43:1927-40.

8. Platto MJ, O'Connell PG, Hicks JE, Gerber LH. The relationship of pain and deformity of the rheumatoid foot to gait and an index of functional ambulation. J Rheumatol 1991;18:38-43.
9. Mondelli M, Giannini F, Reale F. Clinical and electrophysiological findings and follow-up in tarsal tunnel syndrome. Electroencephalogr Clin Neurophysiol 1998;109:418-25.

10. Preston DC, Shapira BE, editors. Tarsal tunnel syndrome. Electromyography and Neuromuscular Disorders. 2th ed. Pennsyvalnia: Elsevier; 2005. p. 365-72.

11. Oh SJ. Neuropathies of the foot. Clin Neurophysiol 2007;118:954-80.

12. Lamm BM, Paley D, Testani M, Herzenberg JE. Tarsal tunnel decompression in leg lengthening and deformity correction of the foot and ankle. J Foot Ankle Surg 2007;46:201-6.

13. Aldridge T. Diagnosing heel pain in adults. Am Fam Physician 2004;70:332-8.

14. Alshami AM, Souvlis T, Coppieters MW. A review of plantar heel pain of neural origin: differential diagnosis and management. Man Ther 2008;13:103-11.

15. Kinoshita M, Okuda R, Morikawa J, Jotoku T, Abe M. The dorsiflexion-eversion test for diagnosis of tarsal tunnel syndrome. J Bone Joint Surg Am 2001;83:1835-9.

16. Jung HJ, Lee SW, Jeong YM, Choi HY, Kim HS, Park HG, et al. The Usefulness of the Preoperative Magnetic Resonance Imaging Findings in the Evaluation of Tarsal Tunnel Syndrome. J Korean Soc Radiol 2012;66:183-92.

17. Vega-Zelaya L, Iborra Á, Villanueva M, Pastor J, Noriega C. Ultrasound-Guided Near-Nerve Needle Sensory Technique for the Diagnosis of Tarsal Tunnel Syndrome. J Clin Med 2021,10:3065.

18. Galardi G, Amadio S, Maderna L, Meraviglia MV, Brunati L, Dal Conte G, et al. Electrophysiologic studies in tarsal tunnel syndrome. Diagnostic reliability of motor distal latency, mixed nerve and sensory nerve conduction studies. Am J Phys Med Rehabil 1994;73:193-8.

19. Davis EN, Chung KC. The Tinel sign: a historical perspective. Plast Reconstr Surg 2004;114:494-9.

20. Preston D.C, Shapira BE, editors. Basic nerve conduction studies. Electromyography and Neuromuscular Disorders. 2th ed. Pennsyvalnia: Elsevier; 2005. p. 25-160.

21. Llanos LF, Vilá J, Núñez-Samper M. Clinical symptoms and treatment of the foot and ankle nerve entrapment syndromes. Foot and Ankle Surgery 1999:5; 211-8.

22. DeQuattro K, Imboden J. Neurologic manifestations of rheumatoid arthritis. Rheum Dis Clin North Am 2017;43:561-71.

23. Bresnihan B. Management of rheumatoid arthritis: synovitis. In: Hochberg MC, Silman AJ, Smolen JS, Weinblatt ME, Weisman MH, editors. Rheumatology. 3rd ed. Edinburgh: Mosby; 2003. p. 907-13.

24. Baylan SP, Paik SW, Barnert AL, Ko KH, Yu J, Persellin RH. Prevalence of the tarsal tunnel syndrome in rheumatoid arthritis. Rheumatol Rehabil 1981;20:148-50.

25. Kane NM, Oware A. Nerve conduction and electromyography studies. J Neurol 2012;259:1502-8. 